\title{
A cross-linguistic data bank for oral picture naming in Dutch, English, German, French, Italian, Russian, Spanish, and Swedish (PEDOI)
}

\author{
Helgard Kremin, Tanya Akhutina, Anna Basso, Jules Davidoff, Martine De Wilde, \\ Peter Kitzing, Antje Lorenz, Danièle Perrier, Mieke van der Sandt-Koenderman, \\ Josep Vendrell, and Dorothea Weniger
}

Centre National de la Recherche Scientifique (CNRS), Hôpital de la Salpêtrière, Paris, France

Accepted 7 May 2003

\begin{abstract}
The well established effect of word frequency on adult's picture naming performance is now called into question. This is particularly true for variables which are correlated with frequency, as is the case of age of word acquisition. Since the work of Carrol and White (1973) there is growing agreement among researchers to confer an important role in lexical access to this variable. Indeed, it has been shown (Hodgson \& Ellis, 1998) that for normal English-speaking adults only the variables 'age-of-acquisition' and 'name agreement' are independent predictors of naming success among the various variables considered. However, when brain-damaged subjects with and without degenerative pathologies are studied, word frequency and word length as well as concept familiarity all give significant effects (Hirsh \& Funnell, 1995; Lambon Ralph, Graham, Ellis, \& Hodges, 1998; Nickels \& Howard, 1995). Finally, it has been suggested that the production of specific error types may be related to such variables. According to Nickels and Howard (1994) the production of semantic errors is specifically affected by 'imageability' and in the recent study by Kremin et al. (2001) 'age of acquisition' predicts (frank) word finding difficulties.
\end{abstract}

(C) 2003 Elsevier Inc. All rights reserved.

\section{Introduction}

Age of acquisition of words, their frequency and concept familiarity as well as name agreement in confrontation naming are culturally dependent parameters. These reasons plead in favour of obtaining specific standards for subjects speaking other languages than English. In this perspective, we analyzed the picture naming performance of more than 1000 adult subjects in order to define the degree of name agreement for several European languages. We furthermore established norms for the psycholinguistic parameters which influence

With the collaboration of Pia Apt, Catherine Arabia, Ria De Bleser, Henri Cohen, Mathilde Corbineau, Marie-Christine Dolivet, Kathi Hirsh, Emilie Lehoux, Mari Noëlle Metz-Lutz, Patricia Montañes, Stéphanie Plagne, Natalya Polonskaya, Mélanie Sirois, Franz Stachowiak, Trione Sweeney, Evy Vish-Brink and many coworkers to be cited in the final version. picture naming performance. If experimental paradigms for naming are to have universal application, comparative norms ought to be obtained from a wide range of languages and populations with different socio-educational backgrounds. We herewith announce the existence of a standardized picture pool for oral naming (PEDOI), standardized, so far, in eight European languages, in Canadian French, and Latin American Spanish.

\section{Method}

\subsection{Studied languages and number of participating} subjects per language

The initial PEDOI study concerned Dutch $(n=120)$, English $(n=120)$, German $(n=130)$, French $(n=120)$, Italian $(n=120)$, Russian $(n=30)$, Spanish $(n=120)$, 
and Swedish $(n=90)$. Data collected for Canadian French (Sirois, Staab, Bélanger, Kremin, \& Cohen, 2000) and Latin American Spanish (Montañes, Kremin, Cabrera, \& Diaz, 1997) will not be considered in this presentation.

\subsection{Controlled individual variables}

Sex (male; female), age (18-39; 40-59; and 60-75) and (with the exception of Swedish and Russian) two educational levels: low-corresponding to 9 years of education; high - corresponding to more than 9 years of education.

\subsection{Material}

Three hundred and ninety black and white line drawings from various semantic fields (including low and high prototypicality items of the 'living' and 'man made' categories, 'body parts,' and 'professions') were presented in free vision, each on one page.

\subsection{Established parameters}

For a subset of 269 pictures/words the following parameters are available:

- Name agreement: it concerns the first oral response given by the native speakers of the studied language. In the sample we present below, the degree of the dominant response is converted into a percentage in order to facilitate the comparison across languages.

- Visual complexity of the picture refers to the judgements of 60 (French) adult subjects on a 7 point scale (from $1=$ very simple to $7=$ very complex). Individ-

Table 1

Dominant responses in eight European languages with percentage of name agreement (NA)-transcription of Russian words with latin letters

\begin{tabular}{|c|c|c|c|c|c|c|c|c|}
\hline & English & NA Eng & French & NA Fr & Dutch & NA Du & German & NA Ger \\
\hline 1 & bricklayer & $85 \%$ & maçon & $93 \%$ & metselaar & $93 \%$ & Maurer & $99 \%$ \\
\hline 2 & elephant & $100 \%$ & éléphant & $99 \%$ & olifant & $100 \%$ & Elefant & $98 \%$ \\
\hline 4 & shorts & $83 \%$ & short & $62 \%$ & sportbroek(je) & $31 \%$ & Shorts & $34 \%$ \\
\hline 5 & saw & $100 \%$ & scie & $89 \%$ & zaag & $98 \%$ & Säge & $66 \%$ \\
\hline 7 & train & $97 \%$ & train & $79 \%$ & trein & $74 \%$ & U-Bahn & $11 \%$ \\
\hline 8 & stork & $70 \%$ & cigogne & $78 \%$ & ooievaar & $97 \%$ & Storch & $98 \%$ \\
\hline 9 & skirt & $98 \%$ & jupe & $98 \%$ & rok & $52 \%$ & Rock & $66 \%$ \\
\hline 10 & waterfall & $90 \%$ & cascade & $75 \%$ & waterfall & $93 \%$ & Wasserfall & $98 \%$ \\
\hline 11 & bell & $100 \%$ & cloche & $100 \%$ & klok & $47 \%$ & Glocke & $96 \%$ \\
\hline 13 & door & $98 \%$ & porte & $99 \%$ & deur & $78 \%$ & Tür & $96 \%$ \\
\hline 14 & mountaineer & $57 \%$ & alpiniste & $74 \%$ & bergbeklimmer & $87 \%$ & Bergsteiger & $99 \%$ \\
\hline 15 & coat & $96 \%$ & manteau & $88 \%$ & jas & $57 \%$ & Mantel & $89 \%$ \\
\hline 17 & whistle & $98 \%$ & sifflet & $100 \%$ & fluit & $96 \%$ & Pfeife & $63 \%$ \\
\hline 18 & tiger & $78 \%$ & tigre & $83 \%$ & tijger & $78 \%$ & Tiger & $82 \%$ \\
\hline 21 & compass & $63 \%$ & compas & $97 \%$ & passer & $88 \%$ & Zirkel & $98 \%$ \\
\hline 22 & motor-bike & $86 \%$ & moto & $89 \%$ & motor & $58 \%$ & Motorrad & $95 \%$ \\
\hline 23 & slug & $69 \%$ & limace & $84 \%$ & slak & $82 \%$ & Schnecke & $86 \%$ \\
\hline 24 & suitcase & $83 \%$ & valise & $91 \%$ & koffer & $84 \%$ & Koffer & $98 \%$ \\
\hline \multirow[t]{2}{*}{25} & chain & $98 \%$ & chaîne & $93 \%$ & ketting & $67 \%$ & Kette & $48 \%$ \\
\hline & Italian & NA It & Spanish & NA Sp & Swedish & NA Sw & Russian & NA Rus \\
\hline 1 & muratore & $98 \%$ & albanil & $31 \%$ & murare & $92 \%$ & kamenshik & $63 \%$ \\
\hline 2 & elefante & $99 \%$ & elefante & $98 \%$ & elefant & $100 \%$ & slon & $100 \%$ \\
\hline 4 & mutande & $42 \%$ & calzoncillos & $4 \%$ & shorts & $76 \%$ & shorty & $73 \%$ \\
\hline 5 & sega & $91 \%$ & serrucho & $16 \%$ & såg & $79 \%$ & pila & $83 \%$ \\
\hline 7 & treno & $88 \%$ & tren & $57 \%$ & tåg & $83 \%$ & poezd & $60 \%$ \\
\hline 8 & cicogna & $49 \%$ & cigüenya & $80 \%$ & stork & $94 \%$ & aist & $70 \%$ \\
\hline 9 & gonna & $99 \%$ & falda & $90 \%$ & kjol & $99 \%$ & ubka & $100 \%$ \\
\hline 10 & cascata & $92 \%$ & cascada & $28 \%$ & vattenfall & $93 \%$ & vodopad & $93 \%$ \\
\hline 11 & campana & $97 \%$ & campana & $99 \%$ & klocka & $73 \%$ & kolokolchik & $97 \%$ \\
\hline 13 & porta & $98 \%$ & puerta & $98 \%$ & dörr & $90 \%$ & dver & $100 \%$ \\
\hline 14 & scalatore & $47 \%$ & escalador & $8 \%$ & bergbestigare & $48 \%$ & alpinist & $73 \%$ \\
\hline 15 & cappotto & $75 \%$ & abrigo & $84 \%$ & rock & $42 \%$ & palto & $37 \%$ \\
\hline 17 & fischietto & $91 \%$ & ato & $45 \%$ & visselpipa & $98 \%$ & svistok & $77 \%$ \\
\hline 18 & tigre & $65 \%$ & tigre & $61 \%$ & tiger & $78 \%$ & tigr & $97 \%$ \\
\hline 21 & compasso & $94 \%$ & compas & $81 \%$ & passare & $83 \%$ & tsirkul & $80 \%$ \\
\hline 22 & moto/cicletta & $84 \%$ & moto & $88 \%$ & motorcykel & $98 \%$ & mototsikl & $100 \%$ \\
\hline 23 & lumaca & $91 \%$ & babosa & $40 \%$ & snigel & $87 \%$ & ulitka & $70 \%$ \\
\hline 24 & valigia & $92 \%$ & maleta & $87 \%$ & resväska & $73 \%$ & chemodan & $97 \%$ \\
\hline 25 & catena & $92 \%$ & cadena & $89 \%$ & kedja & $51 \%$ & tsepochka & $40 \%$ \\
\hline
\end{tabular}


ual variables were controlled: sex $(2) \times$ age $(3) \times$ education (2). The value assigned to a given picture is the mean of the ratings of all subjects.

- Concept familiarity was rated (i) by 98 French subjects (with controlled individual variables) for words and for pictures and (ii) by 107 German subjects for words only. It was rated on a 5 point scale (from $1=$ unfamiliar to $5=$ highly familiar). Since the ratings for words and pictures did not yield any significant difference, we represent the combined means for French concept familiarity as well as the means for German concept familiarity.

- Imageability was rated by 98 German subjects on a 5 point scale where words which easily aroused images were to be given a high rating.

- Age of acquisition was rated on a 7 point scale (from $1=$ early acquired to $7=$ late acquired) by 68 (French) adult subjects (with controlled individual variables). Each point corresponded to an age band of two years thus exploring the period up to 13 years.

NB: Word frequency for the target words in the different languages will not included in the present sample presentation.

\section{Preliminary statistical results}

In order to explore the similarities and/or divergencies between different existing data banks, we first compared the PEDOI values for 'visual complexity' and for 'familiarity' with the corresponding ratings from
Snodgrass and Vanderwart (1980). On the 129 items in common, statistical analysis revealed strong correlations for both visual complexity $(r=.70)$ and familiarity $(r=.89)$. A second analysis concerned the comparison of PEDOI values with the recently obtained new Spanish norms for the Snodgrass and Vanderwart pictures (Cuetos, Ellis, \& Alvarez, 1999). For the 88 common items, the two sets of 'familiarity' ratings were, again, strongly correlated $(r=.93)$. Finally, we compared the frequency of PEDOI target words in French (Imbs, 1970) and in English (taken from CELEX Freq per Million, Nijmegen): the correlation is $r=.77$.

We also assessed the reliability of age-of-acquisition norms. PEDOI values-which concern the estimates of a total of 68 French adults, aged 18-75, with low and high level of education-were compared (i) to the estimates of 78 English students (native and nonnative speakers) collected by Snodgrass and Yuditzky (1996124 common items), (ii) to the 'York' ratings collected from 20 English undergraduates by Morrison, Chappell, and Ellis (1997-131 common items), and (iii) to the estimates of 64 Spanish students from Cuetos et al. (1999-88 common cases). In spite of entirely different subject populations, the cross-linguistic comparisons yielded high correlations $(r=.77 ; r=.70$; and $r=.81$; respectively).

In contrast to the above mentioned parameters, cross-linguistic name agreement (NA) yielded rather weak correlations and was subject to some variation. The comparison of French NA with NA in other languages yields the following correlations: .45 with

Table 2

Sample of established parameters for the 269 pictures and target words

\begin{tabular}{|c|c|c|c|c|c|c|c|}
\hline & English & French & VIS COM & FAM-1 & FAM-2 & IMAG & AoA \\
\hline 1 & bricklayer & maçon & 5.4 & 2.59 & 2.70 & 3.30 & 3.19 \\
\hline 2 & elephant & éléphant & 4 & 1.28 & 2.55 & 4.39 & 2.56 \\
\hline 4 & shorts & short & 3 & 3.35 & 3.27 & 3.47 & 3.41 \\
\hline 5 & saw & scie & 2.5 & 2.6 & 2.55 & 3.87 & 2.88 \\
\hline 7 & train & train & 4.7 & 3.2 & 3.91 & 4.07 & 2.01 \\
\hline 8 & stork & cigogne & 4.1 & 1.35 & 2.29 & 3.87 & 3.6 \\
\hline 9 & skirt & jupe & 2.3 & 3.52 & 3.67 & 4.16 & 2.4 \\
\hline 10 & waterfall & cascade & 4.9 & 1.89 & 2.76 & 3.67 & 4.2 \\
\hline 11 & bell & cloche & 3.2 & 2.66 & 2.52 & 4.00 & 2.35 \\
\hline 13 & door & porte & 3 & 4.79 & 4.52 & 4.61 & 1.5 \\
\hline 14 & mountaineer & alpiniste & 5 & 1.59 & 2.67 & 3.53 & 4.51 \\
\hline 15 & coat & manteau & 2.7 & 3.95 & 3.50 & 4.34 & 1.81 \\
\hline 17 & whistle & sifflet & 2.7 & 1.84 & 2.19 & 3.82 & 2.46 \\
\hline 18 & tiger & tigre & 4.8 & 1.16 & 2.36 & 3.53 & 2.91 \\
\hline 21 & compass & compas & 2.5 & 2.33 & 1.84 & 3.40 & 3.99 \\
\hline 22 & motor-bike & moto & 5.7 & 2.74 & 2.86 & 3.92 & 3.09 \\
\hline 23 & slug & limace & 2.6 & 1.91 & 2.66 & 3.92 & 2.85 \\
\hline 24 & suitcase & valise & 3.5 & 3.55 & 3.38 & 4.55 & 2.86 \\
\hline 25 & chain & chaîne & 4.3 & 2.39 & 3.21 & 4.16 & 2.99 \\
\hline
\end{tabular}

VIS COM, degree of visual complexity (1-7); FAM-1, degree of concept familiarity (1-5) judged by French subjects; FAM-2, degree of concept familiarity (1-5) judged by German subjects; IMAG, degree of word imageability judged by German subjects; and AoA, mean age of acquisition of target word judged by French subjects. 
Spanish, .43 with Italian, .42 with English, .38 with Dutch, . 30 with Swedish, and .20 with German. Comparison of the original Snodgrass and Vanderwart (1980) American NA values with PEDOI French NA yields $r=.22$, their comparison with PEDOI English NA yields $r=.44$.

\section{A sample of entries from the cross-linguistic data bank}

Table 1 represents the dominant response together with the percentage of name agreement on that item for each studied language.

Table 2 represents the parameters which were established for each of the 269 pictures.

\section{Conclusion}

We collected norms for adult oral picture naming in a total of 10 different language communities. The PEDOIstudy controlled for individual variables (age, sex, and education-with the exception of Russian where only highly educated females participated in the study) and established norms for various psycholinguistic parameters thought to influence confrontation naming. Comparison with other data banks showed (i) a high correlation for the degree of visual complexity of different pictures representing the same concept; (ii) a high correlation for the degree of concept 'familiarity' although the estimates concern native speakers of different languages and populations with different socio-educational background; (iii) a high correlation of cross-linguistic comparison of age-of-acquisition norms, and (iv) a high correlation of cross-linguistic of word frequency for French and English target words.

In contrast with the cross-cultural validity of the just cited norms, preliminary statistical results showed that the degree of name agreement on the dominant response is subject to much variation when different languages and/or different populations are considered. Thus name agreement is not only dependent on the known influence of the subjects' individual characteristics (such as age, sex, and education-cf. Kremin et al., 1991). Rather specifically, name agreement is moreover "lexically" related to the precise language under study. Name agreement thus turns out to be the crucial variable for the study of picture naming.

\section{References}

Carrol, J., \& White, M. (1973). Word frequency and age of acquisition as determiners of picture-naming latencies. Quarterly Journal of Experimental Psychology, 25, 85-95.

Cuetos, F., Ellis, A. W., \& Alvarez, B. (1999). Naming times for the Snodgrass and Vanderwart pictures in Spanish. Behavior Research Methods, Instruments \& Computers, 31, 650-658.

Hirsh, K. W., \& Funnell, E. (1995). Those old familiar things: age of acquisition, familiarity and lexical access in progressive aphasia. Journal of Neurolinguistics, 9, 23-32.

Hodgson, C., \& Ellis, A. W. (1998). Last in, first to go: age of acquisition and naming in the elderly. Brain and Language, 64, 146-163.

Kremin, H., Deloche, G., Metz-Lutz, M. N., Hannequin, D., Dordain, M., Perrier, D., Cardebat, D., Ferrand, I., Larroque, C., Naud, E., Pichard, B., \& Bunel, G. (1991). The effects of age, educational background and sex on confrontation naming in normals; principles for testing naming ability. Aphasiology, 5, 579-582.

Kremin, H., Perrier, D., De Wilde, M., Le Bayon, A., Corbinau, M., \& Lehoux, E. (2001). Age d'acquisition des mots et accès au lexique. Revue Neurologique, 157(Supplément au no. 3), 120.

Lambon Ralph, M. A., Graham, K. S, Ellis, A. W., \& Hodges, J. R. (1998). Naming in dementia-what matters? Neuropsychologia, 36, 775-784.

Montañes, P., Kremin, H., Cabrera, A., \& Diaz, A. (1997). Naming of figures. Standardization of the European Community Naming Test in a Latin American population. International Neuropsychological Society (INS), Orlando, USA.

Morrison, C. M., Chappell, T. D., \& Ellis, A. W. (1997). Age of acquisition norms for a large set of objects names and their relation to adult estimates and other variables. The Quarterly Journal of Experimental Psychology, 50A, 528-559.

Nickels, L., \& Howard, D. (1994). A frequent occurrence? Factors affecting the production of semantic errors in aphasic naming. Cognitive Neuropsychology, 11, 289-320.

Nickels, L., \& Howard, D. (1995). Aphasic naming: what matters? Neuropsychologia, 33, 1281-1303.

Sirois, M., Staab, J., Bélanger, S., Kremin, H., \& Cohen, H. (2000). Normes de dénomination et familiarité avec l'objet pour le français québécois. 23e Congrès de la Société Québécoise pour la Recherche en Psychologie. Hull (Québec), Canada.

Snodgrass, J. G., \& Vanderwart, M. (1980). A standardized set of 260 pictures: norms for name agreement, image agreement, familiarity, and visual complexity. Journal of Experimental Psychology: Human Learning and Memory, 6, 174-215.

Snodgrass, J. G., \& Yuditzky, T. (1996). Naming times for the Snodgrass and Vanderwart pictures. Behavior Research Methods, Instruments \& Computers, 28, 516-536. 